\title{
Being close to risk. From proximity to connexity
}

\author{
Valerie November \\ Department of Geography, University of Geneva, 40 bd Pont-d'Arve, \\ 1211 Geneva 4, Switzerland \\ (e-mail: Valerie.november@geo.unige.ch)
}

\begin{abstract}
The relationship between urban spaces, associated risk, and the notion of proximity has until now been subject to very little critical examination. It is, however, crucial to conduct a discussion on the subject, especially in view of the latest disasters that have made the headlines (notably in New York and Toulouse in September 2001, in Madrid in March 2004). On the one hand, it is widely understood that the consequences of risk tend to be more severe in urban environments; on the other, the categorization of different risks (industrial, social, environmental risks, etc.) within a space reinforces the probability of all kinds of disaster occurring. This line of reasoning will be questioned through a case study. By observing the practices amongst the different parties involved in identifying and managing the risk of fire in Geneva (Switzerland), we will propose the notion of connexity as a complement to that of proximity, as it is more closely related to the practices in action in this field.
\end{abstract}

Keywords: connexity, concentration, density, fire, Geneva, geography probability, proximity, risk, urban risk.

Reference to this paper should be made as follows: November, V. (2004) 'Being close to risk. From proximity to connexity', Int. J. Sustainable Development, Vol. 7, No. 3, pp. 273-286.

\section{Biographical note}

Valérie November is a human geographer. She is a lecturer at the Department of Geography of the University of Geneva (Switzerland). Her PhD (in geography, 2000) examined the relationship between the notion of risk and geographical spaces. She spent a year at the CSI (Centre of Sociology of Innovation), Ecole des Mines, Paris, working with Prof. Bruno Latour. She is conducting several research projects on risk and geographical knowledge: on video surveillance in public spaces in Switzerland (financed by the Swiss National Science Foundation), and on flood and urban management (financed by the European COST programme).

\section{Introduction}

The relationship between growing territories, associated risk, and the notion of proximity has until now been subject to very little critical examination. It seems crucial to conduct a discussion on the subject, especially in view of the latest disasters that have made the headlines (notably in New York and Toulouse in September 2001, in Madrid in March 2004): on the one hand, it is widely understood that the consequences of risk tend to be more severe in urban environments; on the other, the categorization of different risks 
(industrial, social, environmental risks, etc.) within a space reinforces the probability of all kinds of disaster occurring.

This line of reasoning must, however, be questioned on two counts: we might ask, initially, which conception of space and which approach to risk it is based upon; then, and even more importantly, we might question whether it accurately reflects what we are able to observe in practice when trying to 'trace' a risk to its source - as suggested by the sociologists of science and technology (Latour, 1999a; Callon et al., 2001) when dealing with sociotechnical networks - and to identify its link to space.

This article will elaborate on three arguments: firstly, by showing the spatial dynamics of the risk of fire, we shall demonstrate that the above line of reasoning is simplistic in nature. Secondly, we shall examine the territorial vision it conveys and the role of proximity it favours. Finally, we shall introduce the notion of connexity [1] as a complement to that of proximity, as it is more closely related to common practice amongst the different parties involved in identifying and managing the risk of fire in Geneva (Switzerland).

The risk of fire was chosen because it is as widely spread in the category of 'natural risks' as in the category of risks called 'man-made risks' (major technological, industrial or even social risks). Moreover, it is generally accepted that the risk of fire comes from heterogeneous sources, whilst this is not always the case for other types of risk [2]. In view of the above heterogeneity, our field of study takes the perspective of the sociology of science and technology, which makes it possible to demonstrate precisely the types of process at hand [3]. As we will see, one can say that a whole collective [4] is working on the risk of fire.

\section{Spatial dynamics of risk}

As Klinke and Renn (1999) point it, risk is based on the contrast between reality and possibility. As defined in The Dictionary of Human Geography, risk is 'the likelihood of a range of possible outcomes resulting from a decision or course of action. Strictly speaking, risk exists when known probabilities can be assigned to these outcomes. Risk is thus distinguished from uncertainty, under which probabilities cannot be established' (Johnston et al., 2000, p. 717). So, in theory, risk can be defined as being something potential, that hasn't occurred yet, but that we foresee will become harmful to individuals or communities in one or several given areas (November, 2002). We can also describe the situation of risk, which is not possible in the context of uncertainty (Callon et al., 2001). These definitions of risk have spatial consequences: risk can be viewed as a projection into the future of signs within a contemporary situation that effectively endanger the space in question (positively or negatively, for that matter). It is constantly the object of a number of individual decisions (leaving or staying in a dangerous area) or of managerial measures for the community, depending on the risk in question (industrial areas, residential areas for example), of regulatory or public policy arrangements which are all in one way or another of its making. In other words, risk has an impact on the future of the territory, because of its power of re-configuration of the collective. In order to isolate the specific characteristics of the relationship between risk and territory, we will first examine the spatial dynamics of the risk of fire. 


\subsection{Concentration and accumulation}

Risk appears to be spread across the space in three ways: it may be introduced along the 'lines of route' of the territory (the networks), or it may be restricted to certain 'meeting points' (junctions), or it may even affect entire 'areas' (the zones). Whether present at a 'meeting point', along a 'line of route', or in an 'area', different categories of risk can accumulate in these risk-prone places.

The risk of fire is linked to certain locations, increasing their vulnerability: motorways, railway junctions, tunnels, gas pipelines, oil storage sites, main transit corridors. The rescue teams then either intervene more at these locations, or take more measures for the prevention of risk. There are specific risk locations (linked to the use of toxic products in some enterprises), which are very localized across the territory, as well as areas of activity that present an accumulation of risk, such as industrial areas and smallscale industrial sites. In terms of geography, sites in a space affected by risk can be divided into three main categories: sometimes, risk is contained within a territorial meeting point, such as railway junctions, or in zones of activity such as clusters of enterprises, oil tanks, or railway stations. They are also to be found along the territorial 'lines of route', such as motorway tunnels and gas or oil pipelines. These 'lines' correspond to the different networks that cross the territory (Raffestin, 1986).

Secondly, the interviewees [5] stated that there is an accumulation of risk in certain locations. They mentioned buildings used as squats (where there is a lot of tampering with electricity, water and gas supplies) and industrial areas, as underlined by a representative for the Department of Urban and Land Planning: 'The industrial area forces us to be very active, because of the growth of small-scale industrial activities in the area, with considerable use of underground spaces, and parking spaces. As a consequence of the economic situation, people have been carrying out casual jobs there, such as body repair work, painting, parties, etc. This has led to an accumulation of risk for others which is not under control, of which people are unaware. People coexist in what are sometimes very risky circumstances ... And interventions in these areas are therefore more frequent. On development sites, risks increase as soon as things become illegal, as soon as one moves away from a minimum of lawfulness. For example, a damaged building will present a number of considerable risks (falling masonry, lifts, etc.), which all add up.' According to the firefighters, particular attention is paid to these areas that present a concentration of activities and people. 'In Geneva, there are lots of places where there is a concentration of risk: like the CFF (Swiss Railways) tunnel at Saint-Jean, through which dangerous products are transported. We have had to set up a whole containment system, including cooling of surfaces, and customised intervention. Files are being created on preventing additional risks. In my view, it is a place with several types of risk.'

What our interviewees said implies that certain zones accumulate a number of risks. This puts a large question mark, in our opinion, on the usual distinction between categories of risk: can one in effect place 'squats' in the category of risks called 'social risks' after listening to the fire inspector who says that it is essentially problems linked to electricity that they fear in these places, as well as hazardous do-it-yourself (DIY) efforts? The same applies to industrial sites. Can one say that these carry only industrial risks if they are a regular venue for parties? And we could also say the same about the problem of density, which surfaced on several occasions as a risk factor, whether it is industrial density, density in the rented accommodation sector, or density of premises visited by the 
public. The categories of risk are thus intertwined once again. The individual level (rented accommodation) and the level of the community (public premises) overlap, in the same way as the public and private sphere do.

\subsection{Dispersion and diffusion}

There is also a second type of spread of risk across the territory that can be recorded; this time it is not based on concentration, but on dispersion and diffusion. It includes risks arising out of the transport of dangerous products, which are present along the main road corridors, as well as the risk of fire, which can occur potentially just about anywhere, as we saw previously. Interestingly, the same interviewees mention the fact that generally speaking, risk is constantly moving around the territory. This applies in particular to the risk of fire, which, at the level of the whole city, represents a rather dispersed threat. A risk of fire may spring out of anywhere and everywhere. 'The dangers aren't necessarily there where we think they are', underlines an inspector in charge of monitoring industrial risks. In other words, the risk of fire is a well-known risk, which is properly controlled; however 'we cannot guard against a bit of DIY that is not protected from tampering', says a firefighter, '(...) risk is ubiquitous: you can't possibly know where the fire will originate: that's the very nature of fire... [at the same time] monitoring facilities and roads enables us to say where the points that present a risk are: such as oil storage tanks. It is important to work on those places to manage the risk of fire'.

So risk seems to be spread across the territory in two particular ways. We made the distinction between the two in earlier research, calling them 'focused risks' (risks concentrated on one site) and 'diffuse risks' (dispersion of risks within a territory). Since then, the distinction seems to have gained ground, as it is also made in the report mentioned above by the French Ministry of Public Works, Transport and Housing (METL) published in 1998, alongside the category of risks called 'territorial risks'. What is particularly interesting here is the switch from the categorization of risks according to their 'nature' (industrial, major technological, social, natural), and to their type of spread on the ground ('network risks', 'territorialized risks' and 'diffuse risks' are the three categories identified by the METL).

Although risk is present on some very specific sites within the territory, it also presents a threat at the level of the whole city. This might seem contradictory at first. Can a risk be diffuse and territorial at the same time, to quote the categories given by Galland (1998) in a report by the METL [6]? Geographers are used to splitting up the territory they analyse into different geographic scales, from the macro to the micro level, through the meso-geographic level, which corresponds to the urban level. According to this division, a certain situation can spread differently depending on the scale of analysis that is applied to it. In practice, according to what our interviewees say, it may be most appropriate to measure several geographic scales simultaneously, as the risk of fire seems to cut across them all (see Cox (1998) for the problematic of scales).

\subsection{Visible 'marks' of risks}

According to the interviews, it would appear that risk not only spreads across the space in an uneven and diffuse way, but also that it contributes to 'putting a mark' on the territory. For instance, the number and position of emergency exits show that risk is taken into consideration in designing the outside of buildings, as do outdoor emergency staircases. 
Architectural rules have also been introduced to guard against the risk of fire, requiring for instance fire-walls that extend above the roof. As underlined by one of the architects questioned, in the city, for example, all link buildings must themselves be self-contained cages that stop the fire from propagating to the neighbouring properties (party walls, independent structures). For architects, it is plain that risk contributes to modifying the territory: 'Yes, it affects the territory, because of certain rules and laws which dictate that buildings must comply with certain specifications; stairwells, external doors in public buildings that have to open outwards for example. These are all small details that don't show at first, but that leave a mark.' The width of roads is also regulated, as is the height of buildings. In other words, the 'urban appearance' is shaped by fire prevention concerns.

Two comments are in order to conclude this first point: Because it is both potential and virtual, one could consider that risk does not play any role in the organization of the territory. It does however have a considerable one. A lot of developments are carried out taking risk into account in order to prevent damage and guarantee security, as we saw with the example of the risk of fire in Geneva. Certain types of risk are introduced 'in depth' into the territory, meaning that they are not easy to eliminate from the place where they emerge [7]. They tend to be 'anchored' in the territory in the long term. The results of this study underline that risk has a constant presence in geographic space and a spatial dynamic, despite its being potential and invisible.

Note must also be taken of the fact that some risks turn into risks of a different category, after the initial risk has been managed. This is something that has already been examined by Theys and Fabiani (1987): they observed that building dams to reduce the risk of flooding generated in particular a risk of erosion downstream. Risk therefore tends to build up in some places and transform over time.

The territory approach highlights the uneven spatial distribution of risk within the geographic space. The word 'territory' has been given many definitions, as examined by Lévy (1999) [8]. However, the concept of territory used in this context does not wholly correspond to the common definitions afforded it, which tend to place physical constraints on one side and human construction on the other. As far as we are concerned, the examples of the risk of fire briefly evoked lead us to conclude that, as regards risk, the territory concerned comes from mix of human construction (political, economic, social and cultural) and of 'non-human' characteristics, in other words environmental characteristics (physical, chemical, organic, etc.) as well as technical dimensions (routes, urban furnitures, etc.).

\section{Territorial indicators used to identify risk}

Having examined the spatial dynamics of risk and observed the various relations that this has with territory, we must now consider the means of identification that are used to determine whether risk exists in a territory. The main concepts used in identifying risk are the proximity between the various elements of a territory, or the effects of distance, more specifically, and density. These concepts are employed in equal measure by actors involved in preventing the risk of fire, those concerned with action, as well as by experts and researchers. 


\subsection{Density and proximity}

In response to the question of whether some areas received more call-outs than others, a Fire Chief said that it depended on the density of the built-up area: 'The more densely built up an area, the greater the number of call-outs to that area. A good example of this is Geneva, where we respond to 6000 call-outs a year, all types of call considered. Out of these 6000 , roughly speaking, 2000 are to the communes and 4000 are to the city of Geneva. This is linked to the density of the built-up area, as in the city there is a concentration and accumulation of all aspects of daily life. Some zones, such as the motorway, do not receive more call-outs, proportionally speaking, than the rest of the area: there is no specific concentration in a given area. We receive very few call-outs to the motorway - we do get some - but it does not constitute a fundamental difference. The densification of the built-up area is an important factor, all values considered, in the industrial and rental sectors as well as in the public buildings sectors. The principle is simple: the more built up an area, the wider the range of activities you will find there.'

The architect interviewed mentioned the fire regulations, which means he has to build in such a way to prevent fire from spreading from one building to the next: 'It is the roof structure that burns most easily, and if it burns the fire must not automatically spread to the neighbouring building. Each time you will see that this is due to an effective and welldefined system preventing fire from spreading, within a certain period of time, to the next building. Yes, the width of the streets. These days you can no longer build anything within three metres; otherwise, the building must have fairly small sides.' A fireman responsible for the hydraulic network explained that the fire service is consulted each time alterations are planned to urban facilities above and below ground: 'I attend a lot of meetings at the Highways Department and the Coordination Committee for Underground Works. The Town Planning Department contacts us each time it plans to modify road layouts, introduce traffic calming measures, build a park or make changes to urban furniture, to see if we agree with its intentions. We still need a $3.5 \mathrm{~m}$ passage to get through, which, I can promise you, is not always easy to achieve!' These interview extracts show that the actors involved are mainly concerned about the distances between the various elements in a territory, spacing measures as well as the concentration of activities, as the basis for their actions and preventive risk management. In practice, they translate these concerns into avoidance distances, regulations preventing buildings from being built near to other buildings, and the creation of free spaces to allow for clearance. Their approach to the environment involves locating potential technical malfunctions by verifying whether the distances set are being observed, activity zones are clearly delimited, spacing measures are in place, etc. These measures act like risk counter measures.

As a result, risk is considered as being closely linked to population density: the more people and activities there are in one area of a territory, the greater the potential for an event with catastrophic consequence arising there.

\subsection{Link with disasters}

Disasters enable us to identify the link between the 'damage' and the type of urbanization, the distribution of the inhabitants and the type of housing. This is an old link if indeed it exists, given that as far back as 1756 Jean-Jacques Rousseau wrote the following words to Voltaire about the Lisbon earthquake of the previous year: 'Without departing from your subject of Lisbon, admit, for example, that nature did not construct twenty thousand 
houses of six to seven storeys here, and that if the inhabitants of this great city had been more equally spread out and more lightly lodged, the damage would have been much less and perhaps of no account. Everyone would have fled after the first tremors and we would have seen them the following day, twenty leagues away, without a care, as though nothing had happened...' (translated from Rousseau, letter to Voltaire on the Lisbon disaster, 1756, as quoted by Fabiani and Theys, 1987, p. 3).

It is precisely from this perspective that the United Nations Programme on the International Decade of Natural Disaster Reduction (IDNDR) was developed (cf. Figure 1). The poster campaign created for the IDNDR World Day in 1996 was highly effective in this regard: the posters showed distinct areas between housing and industrial activities, wide boulevards, and 'solid' buildings as just some of the measures recommended by the UN Programme to promote 'safer' cities.

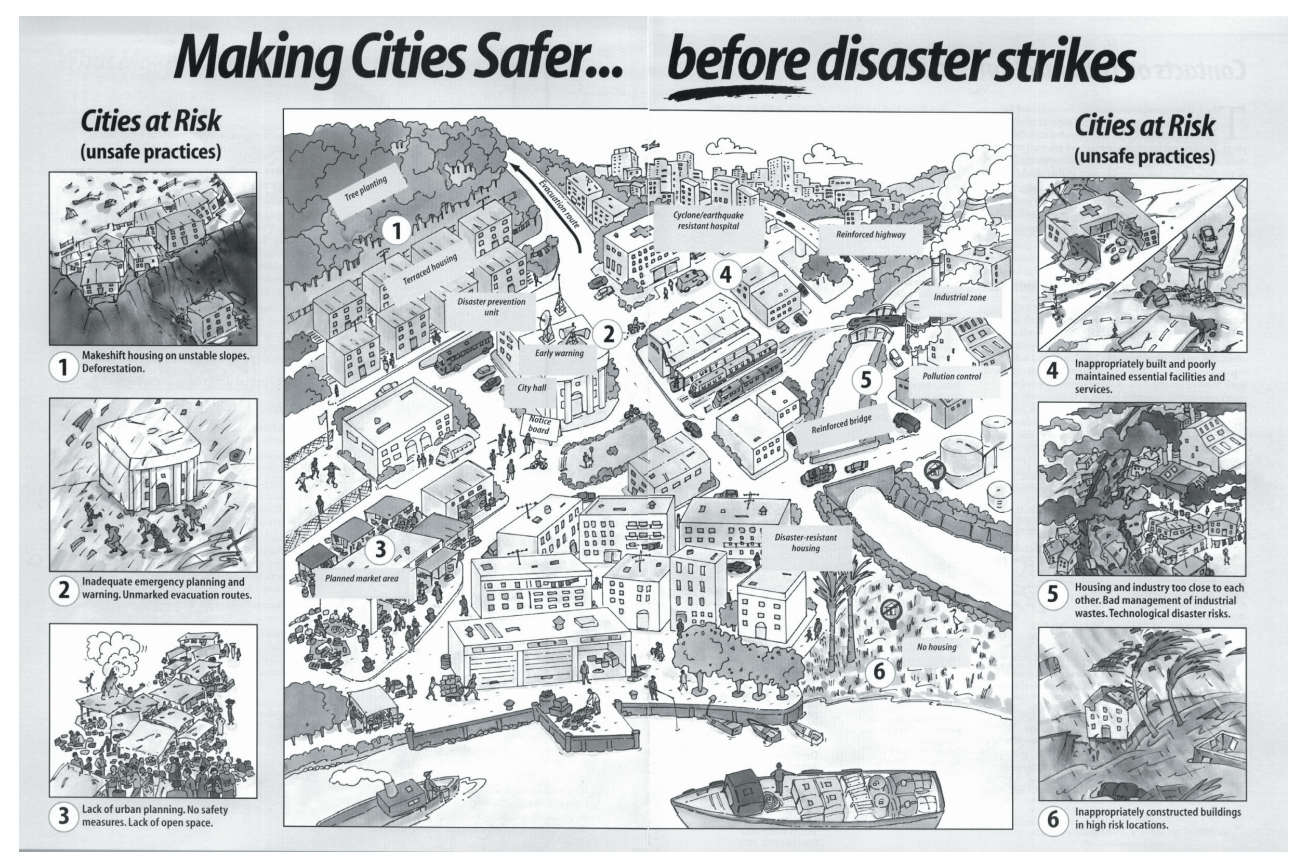

Figure 1 Making cities safer...before disaster strikes. (Source: 'Stop Disasters', awareness campaign for 'Cities at risk' on the occasion of the IDNDR World Day 1996, International Decade for Natural Disaster Reduction.)

Researchers, for their part, employ the same frame of reference to identify risk in a territory. Among others is the work entitled La Ville et ses Dangers (Chaline and DuboisMaury, 1994) in which the two authors highlight population density in one place, or the density of risk in one place as a factor that explains the reasoning behind the territory approach [9]. On one hand, urbanization is viewed as the root of the problem and the reason that risk turns into a disaster, as observed by Blancher in a study on industrial risk in Lyon, 'urbanization has increased the number of people exposed to an accident. It is by making reference to situations such as the chemical corridor that the articles of the Law dated 22 July 1987 were drafted on the taking into account of risk in town planning 
documents, plans for the intervention of the emergency services in the event of major accidents, and the information provided to neighbouring populations' (translated from Blancher et al., 1996, p. 25).

On the other hand, according to this approach, risk management involves deconcentration through reduced densification, by such means as creating green areas and dispersing ghettos (specific population concentrated in one place). The notion of proximity therefore plays a key role in this approach, and disasters become an inevitable frame of reference in the risk identification process. In such a perspective, it can be said that urban growth contributes to changing mere risks into real disasters. And that is precisely why a great deal of construction regulations and techniques and urbanism standards aim first and foremost at avoiding density and reducing proximity between sources of risk and vulnerable elements by various means such as maximum density levels, non-aedificandi zones, and minimum distances with regard to environmental protection facilities.

\subsection{Functional and systemic visions of territory}

This approach to identifying risk is based on a particular vision of territory and the role it plays as regards risk. Implicit in this vision is the idea of the city as a place of many dangers. According to Lavigne and Blancher (1988), this leads to the use of statistics and the laws of probability to explain risk. Density is considered as a factor that increases the impact of an accident. In this perspective, the more people there are, the more risk there is. Promiscuity and proximity are factors, for example, that help to explain the violence and disasters of all kinds that occur there.

Territory is considered as a place in which potentially flawed technical systems are found. As Dourlens (1988) highlights, in this vision of territory 'the city is not viewed as a type of organization which is in itself likely to suffer breakdowns and disruptions. Instead, the urban space is viewed as a place where the consequences of damaging events caused by technical malfunctions can be seen' (translated from Dourlens, 1988, p. 3). There are, however, other approaches to territory to consider, for example the systemic approach. In this approach, a territory is viewed as 'a complex system, made up of a set of sub-systems, which are themselves complex, and that the balance, which is unstable, of such systems is achieved at the cost of an endless number of regulations. These regulations enable the city, which undergoes constant disruption through a series of 'mini-cuts' and 'microbreakdowns', to begin operating again at any given time. Some of these regulations are visible, organized and predetermined, but the majority of them are, on the contrary, spontaneous, automatic and imperceptible' (translated from Vidal-Naquet, 1989, p. 8).

In examining risk in a territory, this approach analyses the concentration of inhabitants, wealth and the flows that form part of the city's make-up. Whereas in the functional vision of territory, risk connotes the technical malfunctions that occur there, the systemic vision of territory views risk as a disruptive threat to the flows of the system (energy, information, capital, etc). In this perspective, urban risk is the intervention of chaos in the flow, in other words stagnation: 'Urban risk means that there is an element in the city than no longer circulates, as though there were a residue in its motion (a build-up) or a stoppage that is not anticipated by the flows therein. Risk and stoppage are therefore linked to the notion of stagnation; anything that stagnates disrupts the urban order and therefore compromises the ability of the city to function normally. The risk is of traffic coming to a standstill, streets becoming blocked, telephone lines becoming overloaded or 
coming down, blocked or flooded sewers, household waste not being collected, or a demonstration or gathering that prevents cars from passing through. In ghettos, minority groups also stagnate, as does waste land that has not been re-injected into the property cycle' (translated from Lavigne and Blancher, 1988, p. 39). The systemic approach therefore favours the various networks just as many places in the system that are most likely to cause an urban breakdown.

In the systemic approach to territory, urban breakdown is the main indicator of the existence of a risk, and the concepts most employed as part of this approach are those of vulnerability and resilience [10], in other words, the ability of the network to cope with a sudden event. What is more, the systemic approach also uses disasters as a means of identifying risk. This is not the only point of reference, however, as the systemic approach also takes account of resilience and vulnerability.

\section{From proximity to connexity}

It appears that concepts such as density and proximity are not the only instruments that enable us to take account of the risk-territory relation. It could be said these concepts do not wholly take account of the 'risk' issue. This is the conclusion that could be drawn on re-examination of the quotations from the study on the risk of fire, in which we noted that the actors do not base their actions solely on the notions of density and proximity, and instead they particularly take account of the notion of the network (both professional and technical) in the risk identification process.

\subsection{Networks}

Three extracts from the interviews on the risk of fire highlight the various types of network: the first concerns the hydrographic network, the second, the communication network, and the third, the professional network. These networks form an integral part of their actions. 'If a tanker overturns at an airport', explains a Fire Chief, 'we must attend to it, but we must also ascertain where the surface waters drain to by quickly analysing the situation, blocking off the Rhone and the lake to avoid polluting them, and returning to the scene of the accident afterwards. Risk identification is all about knowing where the risk is and what it involves, and this information must be established for every situation'. A second Fire Chief added: 'And then there is the information that we receive from the international community. We can find out about a new material that has been developed and new technology, as well as the types of risk they generate. Sometimes we get the information by word of mouth and of course through official communications. (...) Or through publications such as this (Swiss Fire Fighters), which provides page after page on different fires and the problems associated with them, etc.'

The same applied to the introduction of the light railway in Geneva: 'When it came to carrying out the implementation study for the Geneva light railway, we telephoned our colleagues in Tokyo and Montreal - we visit each other regularly, it is not a mafia, rather a gathering of firefighters. There are certain rules of hospitality that apply, rather like a 'compagnonnage' (an association providing professional training and support to people in the same occupation). We ask them to provide us the main thrust of studies they have already carried out and 10 days later we receive the information'. 
The information arrives from Tokyo and Montreal by virtue of a process of interessement [11], and thanks to the information provided, the SIS is able to consolidate its position within the Geneva safety group by putting forward well-reasoned views. This is how the local reality of towns and cities that are far away can have a direct impact on the territorial experience of Geneva.

The networks referred to in the cases mentioned cut through the various geographic scales, as our approach shifts from a very local scale to an international scale. It is particularly interesting to note that all these networks are linked one way or another to territory, as they contribute to its modification or transformation. In this context, the concepts of network and territory are mobilized and it is indeed the notion of 'risk' that links them. We are therefore no longer in a Euclidian space as asserted by Lévy (1999), given that these networks do not operate according to the principles of physical and kilometric proximity. In other words, we are exploring a case-study between what Gilly and Torre (1999) called geographical proximity versus organizational proximity. There are therefore other types of relation between risk and territory that link these terms to the same extent.

\subsection{The benefits of risk}

A second aspect to consider is the 'positive' [12] side to risk, in other words the benefits that can sometimes be gained from risk, and which appear hidden in the functional approach, probably because it centres on the fear of disaster. This was echoed by the architect interviewed: 'Safety at work is of constant concern to our society and I think that within the architectural process, the building site carries the greatest risk. This is a thorny issue, because taking the necessary measures to ensure on-site safety is not cheap. Everyone agrees with paying for railings, protective equipment, etc., but if it is the owner that has to pay out... There is also a kind of pressure between on-site safety and the builders themselves. It ends up costing so much that people can no longer afford to build, so there is a strong economic pressure due to the fact that any measure designed to improve on-site safety will cost money. Such measures are temporary and will not be seen once the building process is complete. The building will be no better or worse in the end if you have taken the necessary safety measures, but they will push up the cost of the build. You have to strike a balance and this is where the whole issue of safety and economic pressure is directly linked to a power struggle at the level of the unions and entrepreneurs. We see this happening and we take measures.'

This argument is also discussed by Zeigler in a work of which the theoretical contribution has been played down (November, 2002). In its analysis of the risk-benefit relation, the authors pose questions such as who will benefit from the taking of risk, who will take the risks and where are these two groups situated geographically? The implication is that those who gain from the operation are those who take the risks. However, they note that this is not always the case. If spatial dimension is introduced into the risk-benefit analysis, there is often a spatial dissociation between those who benefit from the taking of risks and those who take them (Zeigler et al., 1983, p. 35). 


\section{Conclusion}

It appears that the concept of risk has mainly been examined through a functional approach to territories of risk, with little account for the other aspects of risk. These aspects, however, take on greater significance if the spatial dynamics of risk are observed, because it impregnates territory while dying out in networks and simultaneously concerns several geographic scales. The functional vision of territory has consequences for the resulting relation with risk, with the outcome being that territory supports risk and does not interact with it (cf. Figure 2).
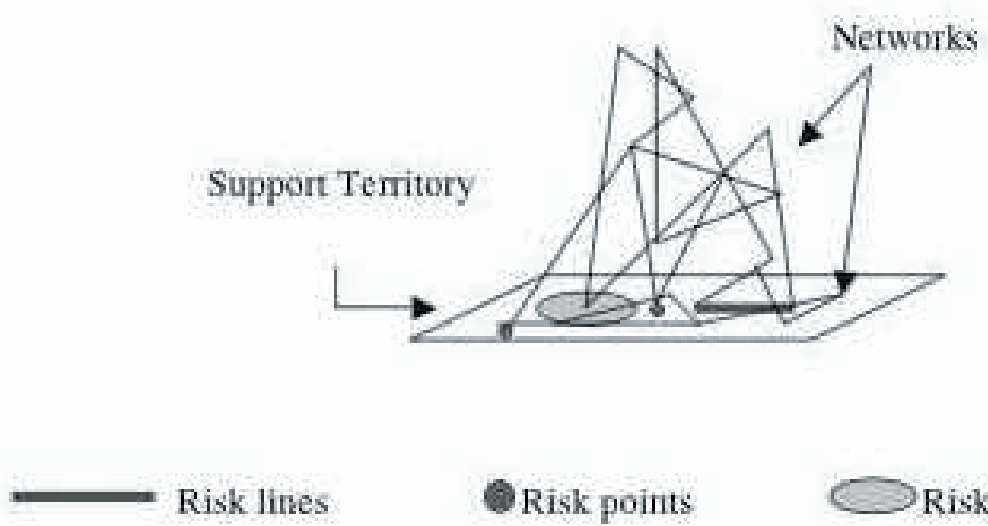

QRisk points

Risk zones

Figure 2 Main conception of risk.

This perspective has its favoured indicators that we have identified in the form of frequent recourse to density and concentration. The relation between risk and territory could be described as a relation of contiguity. In fact, it is essentially the distance between the emergence of risk and the territory concerned that lies at the source of risk identification and the measures taken to counter it.

It is, however, important to link the functional approach to territory and risk to the complex dimensions outlined above, and in particular to the networks that enable risks to be identified and the various geographic scales that this involves.

Taking account of these two aspects simultaneously highlights what can be termed a relation of connexity between risk and territory. Whereas a contiguous relation is based on distance and the connection between the various elements (by employing a frame of reference such as proximity or closeness), a relation of connexity highlights the strong link between the various elements, beyond the physical distance that separates them [13]. The notion that adds weight to our suggested line of reasoning is the notion of interessement. This corresponds in fact to the linking of heterogeneous elements closely together - elements that are therefore different in nature - with a view to creating alliances to strengthen the group, regardless of whether the elements in question are physically distanced or not. 
The relations of connexity that therefore appear to lie at the heart of the issue of risk and territory are particularly difficult to understand if we are to believe Raffestin. According to him, "very little has been done to establish the relation between territorial arrangements on different geographical scales' (translated from Raffestin, 1986, p. 181; see also Raffestin, 1997). This is precisely the point to which the examination of the riskterritory relation has brought us: it reveals on one hand the transcalar character of risk, and on the other the existence of the spatial dynamics of risk. It has been observed, however, that the notions of proximity and density alone cannot translate the resulting geographical complexity. In fact, the notion of proximity does not enable the various geographic scales to be taken into account, given that it comes from the functional vision of territory. The notion of connexity, however, does allow the two to be linked and, as a result, the notion of connexity appears to be a vital complement to that of proximity in the understanding of risk on a given territory.

\section{References}

Beck, U. (1992) Risk Society. Towards a new modernity, Sage, London

Blancher, P., Paquiet, P. and Zampa, C. (1996) 'Industries chimiques et territoire: contraintes et opportunités de développement', Revue de Géographie de Lyon, Vol. 71, no 1, pp. 23-30.

Burton, I. (1982) Vulnerability and Resilience in the Evolution of Cities: a methodological framework and research plan, Institute for Environmental Studies, University of Toronto.

Burton, I. (1983) 'The vulnerability of cities', in Approaches to the Study of the Environmental Implications of Contemporary Urbanization, UNESCO, pp. 111-117.

Callon, M. (1991) 'Techno-economic networks and irreversibility', in Law, J. (Editor) A Sociology of Monsters: essays on power, technology and domination, Routledge, London, pp. 132-161.

Callon, M. (1992) 'Sociologie des sciences et économie du changement technique: l'irrésistible montée des réseaux technico-économiques', in CSI, Ces Réseaux que la Raison Ignore, L'Harmattan, Paris, pp. 53-78.

Callon, M., Lascoumes, P. and Barthe, Y. (2001) Agir dans un Monde incertain: essai sur la démocratie technique, Seuil, Paris.

Chaline, C. and Dubois-Maury, J. (1994) La Ville et ses Dangers: prévention et gestion des risques naturels, sociaux et technologiques, Masson, Paris.

Cox, K.R. (1998) 'Spaces of dependence, spaces of engagement and the politics of scale, or: looking for local politics'. Political Geography, Vol. 17, pp. 1-23.

Dervaux, I. (1983) 'Risque et sécurité', Culture et Technique, no 11, pp. 8-9.

Douglas, M. (1992) Risk and Blame: essays in cultural theory, Routledge, London.

Douglas M. and Wildavsky, A. (1982) Risk and Culture: an essay on the selection of technological and environmental dangers, University of California Press, Berkeley.

Dourlens, C. (1988) 'Villes, risques et périls', Les Annales de la Recherche Urbaine, no 40, pp. 310.

Dubois-Maury, J. (1988) 'Un risque urbain permanent: le feu', Annales de Géographie, no 539, pp. 84-95.

Dubois-Maury, J. and Chaline, C. (2002) Les Risques Urbains, Armand Colin, Paris

Galland, J.-P. (1998) Les risques du Ministère de l'Equipement, des Transports et du Logement. Notes du Centre de Prospective et de Veille Scientifique, no 10, Ministère de l'Equipement, des Transports et du Logement, Direction de la Recherche et des Affaires Scientifiques et Technique, Paris. 
Gilly, J.-P. and Torre, A. (1999) 'On the analytical dimension of proximity dynamics', Regional Studies, Vol. 34, no 2, pp. 169-180.

Jasanoff, S. et al. (Editors) (1994) Handbook of Science and Technology Studies, Sage, London.

Johnston, R.J., Dereck, G., Pratt, G. and Watts, M. (Editors) (2000) The Dictionary of Human Geography, Blackwell Publishers, $4^{\text {th }}$ edn.

Klinke, A. and Renn O. (1999) Prometheus Unbound. Challenges of Risk Evaluation, Risk Classification, and Risk Management. Working Paper no. 153, Akademie für Technikfolgenabschätzung in Baden-Württemberg, Stuttgart.

Lash, S., Szerszynski, B. and Wynne, B. (Editors) (1996) Risk, Environment \& Modernity: Towards a New Ecology, Sage, London.

Latour, B. (1999a) Politiques de la nature: Comment faire entrer les sciences en démocratie, La Découverte, Paris.

Latour, B. (1999b) Pandora's Hope. Essays on the Reality of Science Studies, Harvard University Press, Cambridge.

Lavigne, J.-C. et al. (1988) Dynamique Urbaine et Gestion des Risques: les processus en jeu dans la COURLY, Plan Urbain, Paris.

Lévy, J. (1999) Le Tournant Géographique. Penser l'espace pour lire le monde, Belin, Paris.

November, V. (2002) Les Territoires du Risque: le risque comme objet de réflexion géographique, Ed. Peter Lang, Berlin (in French).

Raffestin, C. (1986) 'Ecogenèse territoriale et territorialité', in Auriac, F., Brunet, R. et al. (Editors), Espaces, jeux et enjeux, Fayard, Paris, pp. 175-185.

Raffestin, C. (1997) 'Le rôle des sciences et des techniques dans les processus de territorialisation', Revue européenne des sciences sociales, Vol. 35, no 108, pp. 93-106.

Renn, O. (1997) 'Three decades of risk research: accomplishments and new challenges', Journal of Risk Research, Vol. 11, no 1, pp. 49-71.

Theys, J., Fabiani, J.-L., et al. (1987) La Société Vulnérable: évaluer et maîtriser les risques, Presses de l'Ecole Normale Supérieure, Paris

Vidal-Naquet, P. (1989) Villes en panne: les arrêts accidentels de la distribution de l'eau à Lyon et à Tours, Centre d'Etude et de la Recherche sur les Pratiques de l'Espace, Lyon.

Vinck, D. (1995) Sociologie des Sciences, Armand Colin, Paris.

Zeigler, D.J., Johnson, J.H. Jr. and Brunn, S.D. (1983) Technological Hazards, Association of American Geographers, Washington, D.C.

\section{Endnotes}

1 As we shall see, the word 'connexity' means that our theoretical framework doesn't come from the spatial analysis. If it did, we would have employed either the word 'connectivity' or the word 'connectedness'.

2 Interestingly, fire as an urban risk has been the subject of very few studies; one of these was the very useful analysis by Dubois-Maury (1988). For an analysis of the risk classification, please refer to Renn (1997) and Klinke and Renn (1999).

3 For a good introduction to this question, please refer to Jasanoff et al. (1994) and Vinck (1995).

4 Despite its use in the singular, this word does not refer to a ready-made unit but to a procedure to collect associations of humans and non-humans (Latour, 1999b, p. 351).

5 Actors interviewed in this study are all involved in the management of the risk of fire in Geneva, in terms of prevention on one hand, and in terms of action in the other: firefighters from the Geneva Fire Brigade, persons in charge of prevention or action in several sections and services in Cantonal Departements (Department of Urban and Land Planning, Infrastructure and Housing; Department of the Interior, Agriculture, Environment and Energy; 
Department of the Economy, Labour and Foreign Affairs; Department for Justice, Police and Transport), architects and The Association of Cantonal Fire Insurance Establishments which work at the federal level. For details of the management of the risk of fire, please refer to November (2002).

6 For the METL, 'territorialized risks' are risks that occur in an area that does not necessarily correspond to the administrative divisions: "The first difficulty, and perhaps the most important, is that the 'natural basin' of a risk (area of foreseeable diffusion of a toxic cloud, of a snow avalanche, of the once-a-century flooding of a river...) does not always fit into the geographical limits of a particular administrative entity.' (Galland, 1998, p. 21).

7 Western society bases its management of risk on the elimination of risk, in as far as that is possible. For a discussion on the anthropological nature of risk in our society, please refer to work of Douglas $(1982,1992)$ and for the embeddedness of risk in environment and society, see Beck (1992) and Lash et al. (1996).

8 The word 'territory' may be used as a synonym for space or place. It may also be viewed from an epistemological perspective, in which case the concept of territory will differ from geographic space; instead it would be an intellectual construction making it possible to take account of the socialized space. Some use the term to mean an area that is limited (by state limits), as a metaphor of animality (an area of power, that is controlled), or as an 'appropriated' space (the territory as an identity and ideal component of the space) and lastly, moving away from the concept of 'milieu' in particular, territory may be a notion that takes account of the identity of individuals and societies.

9 It is interesting to note that these two authors have diluted the importance of this concept in their latest book (Dubois-Maury and Chaline 2002). They now consider urban risk as a sociotechnical assemblage, giving more urban complexity.

11 These concepts were examined as part of the UNESCO Man and Biosphere Programme (cf. in particular Burton, 1982 and 1983).

12 In the approach adopted by sociologists of science and technology, it is the notion of 'interessement', one of the stages in the translation process, which holds together the various elements in the network. The French verb 'intéresser' in this context means 'to impose and stabilize the identity of the other entities and position oneself between them. It is a matter of implementing the networks of alliances created during the previous stage. (...) In addition, the actors involved, seek not only to put forward problematizations, but to impose them and give them greater reality. They put measures of interessement into place in order to divert the other entities away from their objectives and disrupt rival associations' (translated from Vinck 1995, pp. 204-205). As highlighted by Michel Callon, 'the strategies therefore oscillate between attachment (attachment to other actors, holding positions in irreversibilized networks) and detachment (ability to leave a network to create another, etc.). The following notions correspond to the notion of attachment: irreversibility, trajectories, competence, procedural rationality, limited but perfect information, predictability, incremental innovations, hierarchical coordination... Notions such as flexibility, uncertainty, risk, (...) strategic invention, market... are linked to the concept of detachment' (translated from Callon, 1992, p. 62); see also Callon, 1991.

12 The word 'positive' is not used here in a literal sense as the consequence of a risk as such is always negative, but sometimes it is possible to benefit from taking a risk. This is why we can talk in terms of the 'positive' side to risk. According to an etymological study carried out by Dervaux (1983, p. 8), the word 'risk' comes from the Italian risco in the 16th century, which was employed in maritime terminology to mean 'the danger linked to an undertaking', and in military terminology to mean 'a soldier's luck or misfortune'.

13 In this sense, this relation is not only characterized by 'connectivity' or 'connectedness' as developed by the spatial analysis, that measures the high level of existing relationships, but it refers also to the various kinds of relationship developed among the involved collective. That's why the notion of 'connexity' seems more relevant here. 